\title{
Commodification of rural places: A narrative of social fields, rural development, and football
}

\author{
Arnt Fløysand and Stig-Erik Jakobsen
}

Manuscript to be published in Journal of Rural Studies, vol. 23 (2007)

Arnt Fløysand, Professor, Department of Geography, University of BergenFosswinckelsgt 6., N-5007 Bergen, Norway

E-mail: Arnt.Floysand@geog.uib.no

Stig-Erik Jakobsen, Senior Researcher, Institute for Research in Economics and Business Administration, Norwegian School of Economics and Business Administration, Breiviksveien 40, NO-5045 Bergen Norway.

E-mail: stigerik.jakobsen@snf.no 


\title{
Commodification of rural places: a narrative of social fields, rural development, and football
}

\begin{abstract}
One of the most significant recent elements of restructuring in rural areas is the transition from an economy based on agricultural production to an economy based on the countryside as a form of commodity. In this transition process, different narratives or images of an area are produced to promote villages and other places in the countryside as commodities. Much of the literature takes it for granted that outsiders control the processes of branding rural areas, but our case study demonstrates that the producers (as well as potential consumers) of the countryside as a commodity can be insiders within a community. In this paper, we demonstrate how a local football club can take a leading role in the process of commodification of rural places in the postmodern era. Football clubs are presented as commodities to attract investors, sponsors, and expertise from private businesses. In both commodification of rural places and football, the challenge is to construct narratives or images that correspond to the pre-existing expectations of consumers, whoever they might be. Our theory-informed empirical analyses illustrate the way in which the Norwegian football club Sogndal Football has been instrumental in the restructuring of the Sogndal community.
\end{abstract}

Key words: Rural restructuring, commodification, narratives, social fields, football 


\section{Introduction}

The town of Sogndal is a typical Norwegian fjord community where valleys run down to the sea, located in Sogn og Fjordane County in West Norway. Historically, Sogndal has played a rather anonymous role in Norwegian affairs, being endowed with minor land resources but with good soils and scenery appreciated by foreign tourists. In fact, most Norwegians first became aware of Sogndal in 1976 when Sogndal Fotball, a football club from the third league, defied the odds to become runner-up in the Norwegian FA Cup:

In the autumn of 1976, the year of the 50th anniversary of Sogndal Fotball, the club rose from the grey and indistinguishable mass to become a club, and a community, that people from the entire country know by name, or at least have heard of. The reason of course, was the football team, which this autumn made an incredible achievement. Being a club at the third level, Sogndal Fotball went all the way from Fosshaugane [the home ground of the club] to Ullevaal [the national football stadium in the capital city] (Fardal, 2001, p.6). (translated by the authors)

Although Sogndal lost the 1976 FA Cup final, people in the local community and throughout Norway keep returning to the topic of Sogndal Fotball when describing Sogndal. The following narrative of Fosshaugane Campus, structured by the dialectics between key concepts and theories associated with rural restructuring and commodification of rural places and events and processes linked to a stadium upgrade in the community of Sogndal, demonstrates why this is the case.

"Rural restructuring” involves a fundamental process of transformation from one societal form to another, i.e., a shift from an economy centred on agriculture and manufacturing to a more service-centred economy embodying mayor qualitative and quantitative changes in social structures and cultural practices. As such, rural restructurings "are both inter-related and multidimensional in character” (Hoggart and Paniagua, 2001, p.42), but a holistic approach to rural restructuring is likely to create a mega project even if research is undertaken at a single locality. Our narrative prioritizes the social construction of the countryside by the dominating actors within the community and downplays the multiplicity of other actors who produce rurality. In 
recent restructuring of rural areas different narratives or images of an area are produced to promote villages or other places in the countryside (Woods, 2005). Our narrative demonstrates how football in the post-modern era can take a leading role in such shifts in society "from landscapes of production to landscapes of consumption” (Cloke, 2006, p.19). Much of the literature takes it for granted that outsiders control the processes of branding rural areas. The "tourist gaze”, or representations of rural areas as attractions in the form of a rural idyll, wilderness, or place of adventure, has been produced on this basis (Urry, 1990). Our narrative supports those who argue that the consumers and producers of the countryside as a commodity can also be "insiders", such as those individuals living in a rural community, newcomers, local firms, politicians, and even football clubs. These agents demand representations that are different from those of the tourist gaze. In many respects, commodification of rural places has a parallel within football, where clubs are represented as commodities to attract investors, sponsors, and expertise from public and private interests. In both cases, the challenge is to construct narratives that correspond to the pre-existing expectations of consumers. The presented narrative also supports the argument that, to emphasize rural space as a socially produced set of manifolds, "it seems fruitful to bring together material and imaginative conceptions of rural space through their intersections in particular practices” (Cloke, 2006, p.24).

In this paper, we analyse such a practice via a study of an emerging rural development project in the municipality of Sogndal, Norway, by asking the following questions:

- What is the position of the Sogndal Fotball Club in Norwegian top-level football and in the community?

- What are the social field dynamics behind the narrative Fosshaugane Campus?

- In what way can the case study inform theories on rural restructuring focusing on commodification of rural places?

In Section 2, we outline our theoretical position and discuss the concepts of rural restructuring, commodification, narrative, and social fields. Our study of the way in which narratives and rural restructuring are shaped by football is based on the argument that narratives are not universally shared, but that the dominance of certain narratives in certain social fields (Grønhaug, 1974) is fundamental for the coordination of rural restructuring. In Section 3, we document 20th century 
industrial transformation in Sogndal, and we document changes that occurred within the Sogndal Fotball Club, concentrating on events and processes at different geographical scales that underlie the increased professionalism and turnover of the club and how these factors influenced the organization of the club. In Section 4, we demonstrate the way in which the art of networking has turned a stadium upgrade into an act of rural development, as represented by the project Fosshaugane Campus. Via Fosshaugane Campus, the football club has contributed to the commodification of the village of Sogndal by narrating the rural not as wilderness or a place of adventure for tourists, but as a place for sport, development, and innovation for creative (young) people. Section 5 concludes the discussion. We argue that Sogndal Fotball is an example of how the increased professionalism of an organization in a glocal world can change football from a game of 22 players to a game of material and imaginative rural development practice involving the main actors within a community.

The data presented in our analysis are adopted from an ongoing project that examines the organization of top football clubs in Norway, in which several clubs are being investigated by a research team. In this paper, we report the findings of the analysis of one of these clubs. The case study is based on interviews with people who are or have been part of the club or are connected to the club, such as managing directors, board members, investors, sponsors, and representatives of local authorities and other important local institutions. We also use information from existing documents and published literature.

\section{Spatial rural restructuring: towards a methodology}

\subsection{Theoretical discourse: setting the scene}

One traditional line of thought in studies of rural development has been the issue of spatial classification and measurement. During the 1950s and 1960s, this classification of rural settlement, form, and distribution became highly standardized and precise (e.g., Chisholm, 1962).

Another long-established tradition within rural studies, and one that is closely related to disciplines such as anthropology and sociology, is studies of kinship and community relations (e.g., Williams, 1963). With a focus on social relations and culture, these studies represent a 
clearly different approach than the positivistic tradition of classification that emphasizes visible material entities (Phillips, 1998).

The restructuring approach was developed as a critique of these traditions, claiming that these studies were either too empiricist or too partial in their analyses. There was also a lack of understanding of the political dimension (Cloke, 1989). Marsden (1995), among others, called for a more integrated, holistic, and spatial approach to understanding rural transformation. There is a multiplicity of causal forces that affect rural restructuring, and these forces can be played out in dissimilar ways in different places. This holistic perspective implies an understanding of the interdependency between social, political, cultural, and economical processes. The term "rural restructuring” is linked to a transformation from one societal form to another, i.e., the shift from an economy centred on agriculture and manufacturing to a more service-centred economy involving a commodification of the countryside. Some have seen this new service class as a “colonizer” of rural areas, bringing new ideas and new forms of living to the countryside (Thrift, 1987); however, Urry (1995) concluded that, even if change has taken place in rural areas with the growing importance of leisure and consumption, this cannot be described simply in terms of the service class remaking rural localities.

An alternative theoretical framing to the materialism of the restructuring thesis is the social construction approach, representing a cultural turn within rural geography (Phillips, 1998). This approach invites studies on “...how practice, behaviour, decision-making and performance are contextualized and influenced by the social and cultural meaning attached to rural places” (Cloke, 2006, p.21). This involves emphasizing the striking heterogeneity in processes of rural restructuring and practice. Previous studies have differentiated between various discourses of rurality according to their social identities. Images of the countryside have been related to such categories as sexuality (Bell and Valentine, 1995), race (Kinsman, 1995), and gender (Little and Austin, 1996). A special emphasis has been placed on the rurality of the neglected rural others, such as the elderly, unemployed, and ethnic minorities (Phillips, 1998).

Despite its novelty, there has been notably criticism of this cultural turn. It has been argued that this approach dematerializes social science through its preoccupation with immaterial processes 
and the constitution of intersubjective meanings (Cloke, 2006). It is also claimed that the approach depoliticizes social science by drawing attention away from analyses of social-political struggles and political intervention. Furthermore, the emphasis on social construction has resulted in the downplaying of the implications of such a construction (Gregson, 1995).

The point of departure for our approach is the recognition of the multiplicity of social practice in rural areas where the distinction between rural identities and urban identities has become increasingly blurred and where individuals are influenced by events and processes at various geographical levels. To believe in the capacity of rural people to participate in all stages of economic development requires a focus on social practice and knowledge production of groups often not considered as important in studies of rural restructuring such as football clubs. Recalling the critique of traditional lines of thoughts in studies of rural development, we wish to avoid a holistic approach that runs the risk of sliding towards empiricism. Thus, in this study we focus on a specific sphere of rural restructuring; the commodification of the place of Sogndal, and discuss how the case informs theories on rural restructuring concerning commodification of rural places. It goes without saying that other institutions and structures do not have casual effects on rural restructuring. Secondly, we also want to avoid the anti-materialism of the social construction approach. By introducing the concept of "social field”, presented later in this section, we analyse how material and imaginative conceptions of rural space are interconnected in various practices.

The type of organization that we emphasize in our analyses of rural restructuring is often overlooked in traditional studies. Popular myths hold that sport, and especially football clubs in a European context, can be a binding thread in rural areas, contributing to local identity and a sense of community (Cashman, 2002). However, despite the popularity of such myths, there is a lack of analyses on how the social, cultural, and economic dimensions of sport contribute to the processes of community development (Tonts, 2005). In any regard, certain studies have emphasized the interdependency between football clubs and the surrounding locality. For example, Hamil (1999, p.4) stated that “...football is different from other industries because it's fundamentally about the community and not the individual [it is] a sense of shared emotional ownership,” while Morrow (2003, p.55) has portrayed football clubs as “...a representational 
sport with clubs representing geographical locations.” In an analysis of the small Scottish town of Kirkcaldy, Hague and Mercer (1998) demonstrated how the local football team (Raith Rovers) helped to create a sense of identity and a strong attachment to the locality. The novelty of our approach is an attempt to link the theme of football with a theoretical framing of rural restructuring, a link that rarely has been made in the past.

\subsection{Processes of rural restructuring: the commodification of rural places}

Our analysis of rural restructuring in a post-modern world is based on the mapping of relations between shifts in narratives, production, and social fields in a given area. As a consequence of “time-space compression” linked to technological innovations and political constructions of worldwide systems of transfer, capital and narratives cross borders at an increasing tempo; this has shaken established geographical patterns of relations. The result is a complex set of social, political, and economic restructurings that enable new forms of political positions. Swyngedouw (2004) argued that globalization should be seen as a recasting of these processes both "upwards" and “downwards" in scale, rather than being reduced to an upscaling of social, political, and economic processes.

Recent processes of globalization have intensified the restructuring of rural areas. Technological innovations and the construction of global transfer systems have caused changes in economic, political, and cultural relations, with important effects on most activities in rural communities. These restructuring processes "are both inter-related and multi-dimensional in character" (Hoggart and Paniagua, 2001, p.42), and there seems to be a shift from a landscape dominated by production to a landscape in which consumption has a more prominent position (Cloke, 2006, p.19). During the 1980s and 1990s, rural European communities faced increasing international competition and political liberalization that caused a shift in farming practices towards larger farm units and reduced employment within the agricultural sector. Increased mobility has increased the flow of people in, out, and through rural spaces; tourism is a sector that is demonstrating growth. Different forms of rural tourism have changed the main economic activities of rural people from traditional agricultural activities and provided their communities with new sources of income. 
It is assumed that the countryside has become a "commodity" to be bought and sold (Little and Austin, 1996). This assumption is related to a wider debate on the commodification of society that can be traced back to Polanyi's (1957) work on the "great transformation” from a non-market society to a market society. Polanyi analysed a shift in the balance of the economy from the noncommodified to the commodified sphere. This process has accelerated since the publication of Polanyi's work. The logic of the market is invading greater portions of everyday life, and even if this commodification is not yet complete, the reality is that increasing numbers of the activities that occur in society are mediated via the market (Watts, 1999). The term "commodification" refers to the process by which goods and services are increasingly produced by capitalist firms for a profit under the conditions of market exchange. According to Williams (2002), commodification has three distinct elements: goods and services are produced for exchange; exchange is monetized and conducted under market conditions; and the exchange of goods and services is motivated by the pursuit of profit. Woods (2005) identified five main elements of commodification of the countryside: the marketing of rural production sites as tourist attractions; the repackaging of rural heritage, creating the "tourist gaze" of the rural idyll based on nostalgia; the promotion of "fictional" rural landscapes whereby the tourist gaze is informed by fictional representations of rural life and landscape; the rural as a site for extreme experiences via adventure tourism that extend beyond the metaphor of the tourist gaze; and the use of rural areas as a brand in the marketing of premium food and craft products.

The commodification and marketing of rural places commonly means re-packing and representing rural areas and features to emphasize those characteristics associated with the rural idyll (Little and Austin, 1996). Urry (1990, p.3) argued that:

The 'tourist gaze' [that] is directed to features of landscape and townscape which separate them off from everyday experience. Such aspects are viewed because they are taken to be in some sense out of the ordinary. The viewing of such tourist sights often involves different forms of social patterning, with a much greater sensitivity to visual elements of landscape or townscape than is normally found in everyday life. People linger over such a gaze, which is then normally visually objectified or captured through photographs, 
postcards, films, models and so on. These enable the gaze to be endlessly reproduced and recaptured.

In summary, the concept of the tourist gaze highlights the fact that one of the most significant elements of rural restructuring seems to be the transition from an economy based on agriculture and manufacturing to an economy based on consumption and the countryside as a form of commodity (Murdoch and Marsden, 1994; Urry, 1995; Woods, 2005; Cloke et al., 2006).

Commodification of the countryside also implies a new mentality among the involved actors. Writings on regional development have stressed learning, knowledge, flexibility, networking, and innovation as essential features of regional restructuring. Time-space compression and increased competition in the economy mean that the specific capabilities of actors within a region are essential for competitiveness (Morgan, 1997; Maskell et al., 1998). Successful places are often characterized by an entrepreneurial culture that has developed over long periods. Such local milieus build upon a variety of channels to access impulses and relevant knowledge from different localities. There is commonly the coexistence of a "local buzz" that facilitates localized knowledge spillover and external "pipelines" (Bathelt et al., 2004); however, many rural areas lack this type of entrepreneurship and local buzz. Rural restructuring has often been orchestrated by external actors or "outsiders", resulting in a situation of dependency for the local community (Jakobsen et al., 2005a). Thus, there is a need for local entrepreneurs to ensure that a development helps the region to prosper.

\subsection{Understanding commodification of rural places: narratives, social fields and networking}

The picture of outsiders as dominating the commodification of the countryside is a striking feature of the literature that analyses the tourist gaze. This literature concentrates on outsiders who produce "fictional" images of the countryside; however, such studies have been criticized for being biased because they ignore commodification of the countryside arranged by "insiders" (Ilbery, 1998; Cloke, 2006). They also rule out the possibility of insiders being the target consumers during the commodification process. To avoid this problem, our first step is to consider the tourist gaze as just one of multiple representations of places (Urry, 2002). Different 
representations of a place are produced to market villages or other areas in the countryside as attractive to both outsiders and insiders. In such settings, one can use the concept of "narrative" to label the wider system of representations that are in general use concerning a certain place, where "representations" can be related to the specific perceptions of an actor or a group of actors (Haarstad, 2005; Halfacree, 2006).

Thus, a narrative can be defined as a string of socially constructed representations (ideas, sayings, and stories) about people and the world that are tied together in a whole that has a coordinating role in terms of social relations and conduct. In our case, the focus is on representations that have a coordinating role in rural restructuring. Accordingly, a narrative organizes strings of representations. In the case of the commodification of rural places, such narratives are commonly selected to correspond with pre-existing expectations of potential consumers, such as tourists. Their representations of the rural as attractions in the form of the rural idyll, wilderness, and a place of adventure are common; however, the potential interpreters of a representation include those people living in the community, potential immigrants such as students, relocating firms, and politicians. The target consumers can even include football players. Football players, villagers, potential immigrants, and relocating firms are attracted by different representations than those that attract tourists. In the case of multiple actors as potential producers and consumers of rural representations, the challenge is to perform a narrative that combines different representations in such a way that it is accepted by the hegemonic interest groups represented in the rural community and by multiple consumer groups outside the community.

The above discussion dictates that constructions of rural narratives must be seen as a dynamic, ongoing, socially constructed process that involves many social actors who continuously reshape the narrative and transform it to fit their perceptions, needs, values, and agendas (Hall et al., 2003). Rather than understanding material, imaginative, and practised ruralities as being separate, it is advisable to see them as intrinsically and dynamically intertwined with real-life relationships (Cloke, 2006; Halfacree, 2006). The construction of narratives takes place in spatial social networks or changing sets of social relations between various actors of different scales that involve material, social, and symbolic exchanges. 
To capture the material and imaginative dimension of rural practice, we introduce our final methodological element: the concept of social fields (Fløysand and Jakobsen, 2002). A “social field” is a collection of geographically and historically distributed social networks coordinated by formal and informal rules of conduct in a given material, practised, and imaginative setting. A social field can be described as an arena for producing and communicating various presentations.

Our concept of social field is informed by the social network literature (Burt, 1992; Granovetter, 1992). A field, or a network system, consist of a number of actors or nodes that are linked by various social relations (Walker, 1988). In addition each field are connected to other fields through individual and collective linkages and relations. Our concept of social field highlights both the structure and the content of such social network system. The structure, or "material setting”, of a social field, in terms of the historical and geographical scales of a field, is empirically defined by referring to the number of actors and their relations in a particular social field and their distribution in time and space. Hence, the scale or "physical shape" of a social field is defined by the number of people involved and their extension in socio-physical space.

The content of a social field is related to how it both constrains and enables the agency of actors. A number of social relations become a social field when a task-solving network system is observed to frequently produce and maintain relations. Hence, a social field represents a particularly dense pattern of social relations. Within the social network literature there is an emphasis on how the attitudes and behaviour of actors is strongly affected by their position within such networks of relationship (Nohira, 1992). Thus, the practice of individuals, or the "practised setting” of a social field, must be analysed by referring to individuals position within a certain field and the status of this field compared to other relevant field, i.e. hegemonic social field versus non-hegemonic social fields.

Networking between individuals involves knowledge sharing, building of trust and the development of shared rules and inter-subjective meaning. The existence of interpersonal trust in dense network means that individuals are more willing to get involve in risky operations without fear of sanctions from outsiders. It also makes individuals more willing to act as a group in support of common mutually beneficial goals reducing the possibility of individual opportunism 
(Gordon and McCann, 2000). Further, it has been argued that commonly shared practices and conventions between co-located actors can create a culture for cooperation that are an important asset in process of regional development (Amin and Cohendet, 1999). Such inter-subjective meaning and shared rules, that can be produce in the form of narratives, are the "imaginative setting” of a social field.

Pursuing a social field approach involves the study of the dynamics between events and processes in different fields (Fløysand and Jakobsen, 2005). Our approach assumes that such dynamics of social field systems are shaped by micro-macro processes of dominance. Social fields are interconnected within the actor in the sense that each person possesses various positions with a number of linkages that together form the totality of fields that comprise his or her relational space. Social persons or groups of social persons normally take part in various social fields of contrasting material, practised, and imaginative settings; for instance, via family relations, neighbour relations, community relations, and market relations. In such fields, people participate by performing narratives that are legitimized via shared expectations of how relations should be conducted and how the world should be viewed. A social field must be discovered through empirical descriptions. The question of dominance has to evolve by empirically embedded discussions on the number of social fields, their distribution in time and space, and the existence of power relations.

Recalling the definition of to the term "rural restructuring", we approach the phenomenon focusing on qualitative and quantitative changes linked to commodification, i.e. a shift in the balance of the economy from the non-commodified to the commodified sphere, including the representing of rural areas to market the countryside as attractive to both outsiders and insiders. It is a dynamic, ongoing, and socially constructed process that also includes the practices, perceptions, needs, values, and agendas of people living in the countryside. To capture such processes of commodification we have introduced the concepts of "narrative" and "social fields". A "narrative" labels a wider system of representations of a rural place, a "representation” a specific perception, while a “social field” labels a particularly dense pattern of social network where social practice and the production and coordination of narratives and representations to market the countryside take place. 
In the case of the town of Sogndal, Norway, the narrative of Fosshaugane Campus is a key element of an ongoing process to market the place. Fosshaugane Campus is a development project that combines sport, education, and research activities. The project is rooted in the interaction between (a) the transformation of the place Sogndal and shifting representations of Sogndal, (b) growth in the turnover of the football club Sogndal Fotball, (c) the adoption of a more professional and uniform organization of the club, and (d) new regulations for football in Europe. It should be emphasized that the project is dominated by a social field of local scale rather than outsiders, whereby the supply of resources is organized by joint action between the club and local public authorities.

\section{Sogndal and Sogndal Fotball}

\subsection{The place of Sogndal and industrial transformation in the 20th century}

Sogndal holds a peripheral position in Norway, even though its location meant that from early on the town served as a local hub of communications, trade, and services in Sognefjord. From its formation, the community was situated on good soil that stimulated agricultural development in combination with forestry and fruit orchards. Well into the 20th century, Sogndal remained a community based mainly around primary industries. Tourism in the area also has an extended historical record, having developed primarily in the 19th century as an elite pursuit of the upper classes in search of exotic sites. As such, Sogndal was introduced early on from the viewpoint of a tourist's gaze:

What a wonderful village Sogndal is! We looked at it from different spots, everywhere the views are gentle and picturesque, and form an excellent contrast with the fiord situated beyond the genuine Bergen Mountain with snow on its crown. The river that runs through the valley, with its beautiful cascades and small archipelagos, creates a striking sensation in the painting. (Bishop J. Neumann, travelogue from 1823, quoted in www.sogndal.kommune.no) 
Later, regular cruise services and the construction of new roads vitalized local tourist activities and the place. During the first half of the 20th century, a shift occurred from subsistence to commercial agriculture based on agricultural goods such as dairy and raw forest materials produced from sawmills. The next industrial transformation took part at the end of the century. During the first half of the century there was little change in population, increasing from 3479 in 1900 to 3896 in 1960; in 1970 the population was 4452, with 2081 people being industrially active. The dominant sector at this time was agriculture; followed by services and real estate; construction, transport, and communication; manufacturing (dominated by agro-industries); and trade, hotels, and restaurants (see Fig. 1).

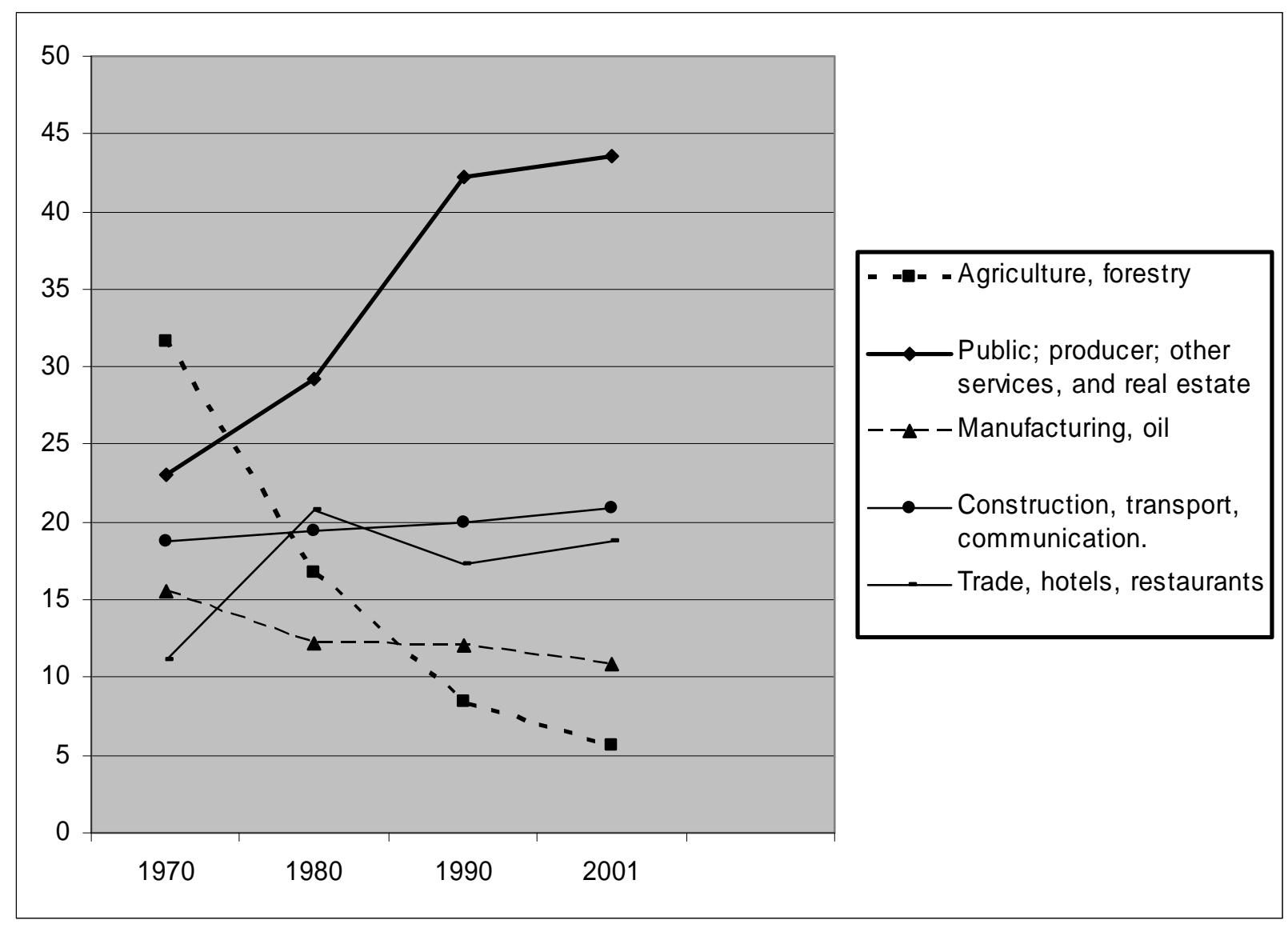

Figure 1:Industrially active persons in Sogndal by industrial sector, 1970-2001. Data represent percentage shares of the total number of industrially active persons.

Source: Statistics Norway. 
In 2001, Sogndal numbered 6581 inhabitants, with the industrially active population having increased to 3670 people. In addition, the employment structure had changed dramatically. During the period 1970-2001, the proportion of workers employed in agriculture had dropped from $32 \%$ to $6 \%$, and the manufacturing sector, dominated by agro-industry, had also suffered a decrease in its share of the total employment. The booming sectors during this period were trade, hotels, and restaurants, which increased its share of total employment from $11 \%$ to $19 \%$, and services and real estate, which increased its share from $23 \%$ to $44 \%$.

Figure 1 portrays a change in activities that in the literature is termed a shift "from landscapes of production to landscapes of consumption". A deeper examination of the statistics also reveals substantial changes within sectors. The introduction of new technology has caused substantial productivity gains in agriculture and affiliated manufacturing activities. In addition, increases in the sizes of farms have resulted in productivity gains in agriculture. Hence, these sectors have maintained their production despite substantial reductions in employment. In the services and real estate sector, the changes have mainly resulted from growth in public services. The proportion of the workforce employed in public services increased from $14 \%$ to $30 \%$ over the period 1970 2001.

The development of service activities in Sogndal follows the national trend. Not only were many new jobs created, but many were decentralized, particularly to marginal rural areas such as Sogndal. However, in Sogndal the increase in services is strongly linked to growth in education activities. In 2001, the proportion of active people employed in the education sector in Sogn og Fjordane County was the same as the national average of $8 \%$, while in Sogndal this figure was 14\% (Statistics Norway). Hence, the education sector employs a higher share of industrially active people in Sogndal than in most rural areas in Norway. The reason behind this trend is Sogn og Fjordane University College. Established in 1972, the college has grown into a medium-sized university college that plays a key role as an employer in the community. The college is located in three municipalities within Sogn og Fjordane County (Sogndal, Førde, and Sandane), but the main activities of the college are located in Sogndal, as are about 1700 of the total of 2100 students and 250 faculty and staff. Recalling the small total population of the community, it is clear that the college is significant in a variety of spheres of life in Sogndal that are not revealed 
by macro data; this includes the sphere of football.

\subsection{Sogndal Fotball: Sport results, sports facilities, and turnover}

Sogndal Fotball is the only actor that matches Sogn og Fjordane University College as a catalyst for development in Sogndal. The first indication of the catalyst role of the club is apparent when entering Sogndal. At the main entrances to the community, visitors are welcomed by locally designed signs placed in front of the standard blue-coloured signs used to identify municipalities in Norway. The welcome signs contain the logo of the football club at the top, with a subtext surrounded by the logo of the Municipality encouraging the visitor to “join the team” (Fig. 2).

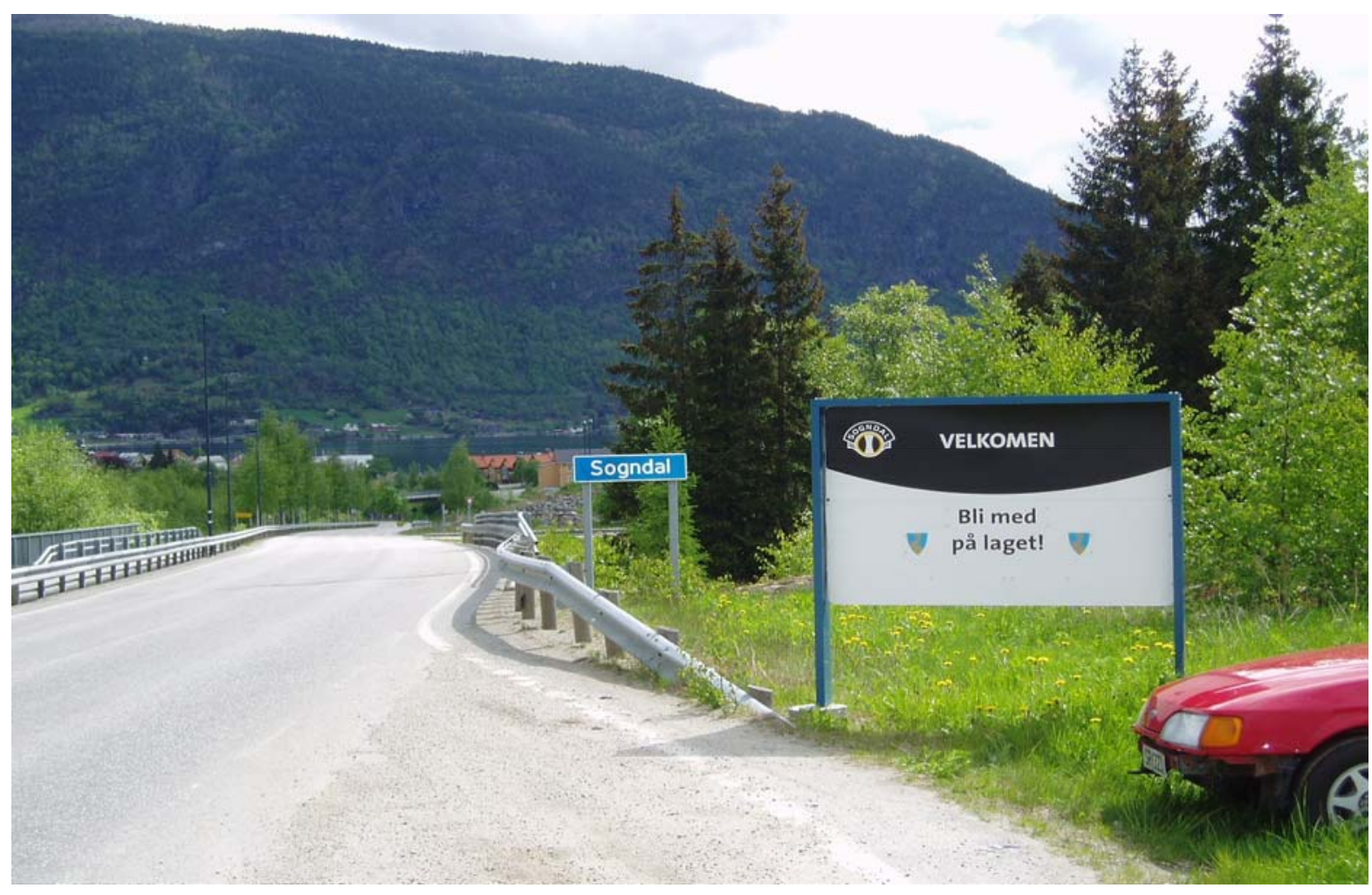

Figure 2: The locally designed sign welcoming visitors at the entrances of the Sogndal community.

Photo: Ole Martin Hitland. 
As already mentioned, the club first occupied a key position in the community when it become runner-up in the 1976 Norwegian FA Cup while playing at the third league level. The team qualified for promotion to the second division during the same season. In 1981, the club was promoted to the top league for the first time, with a team built around key figures from the 1976 side. This rapid rise pushed Sogndal to the forefront of the national popular media. Promotion to the top league in 1981 was celebrated by local government, and a gala banquet was arranged by the local authorities:

...I will claim that no historical event, no enterprise or individual, has made the community of Sogndal as renowned throughout the country, as the football team (Sogndal Mayor speaking at the gala banquet, quoted in Hompland 1982, p.16)

However, the club was relegated the following season. Its best result during the 1980s came in 1988, when the club placed sixth in the top league, but it was during the 1990s that the club experienced its most successful period. Since 1990, Sogndal Fotball has qualified for the top league in nine seasons (Table 1). Before returning to the first division in 2005, the club played four successive seasons in the top league. Even though the club did not win any major trophies, the results are impressive given the limited human resources available in the town.

The success of the football team was followed by huge changes in sports facilities within Sogndal. The involvement of the club in developing facilities soon exceeded normal standards. In addition, from the very beginning Sogndal Fotball promoted processes that strengthened ties between sport, education, and rural development. The club was the key player behind the construction of a new stadium for track sports in 1985 (Sogndal Stadium), a stadium for football constructed in 1988 (Fosshaugane Stadium), a large training area for football constructed in 1988 (and extended in 1998), and two indoor sports halls constructed in 1985 (SIL-Tribuna) and 1998 (Sognahallen). The Sogndal Stadium and SIL-Tribuna are multi-function facilities that combine to satisfy the requirements for a stadium for track sports in the county, educational facilities for Sogn og Fjordane University College, a sports hall for students of the college and Sogndal Secondary School, and a new football ground and stadium for the football club. The college also played its part in the success of Sogndal Fotball during the 1970s and the following years by 
recruiting talented football players, who combined sport and studies in the community, and establishing a sport study program in its curriculum that had a direct effect upon the demand on sports facilities developed by the football club.

Table 1:League rankings of Sogndal Fotball during the period 1981-2005.

\begin{tabular}{llll} 
Season & Position & Season & Position \\
& & & \\
\hline 1981 & Winner of the 1 division (promoted) & 1994 & $\mathbf{1 1}^{\text {th }}$ in the top league (relegated) \\
1982 & $\mathbf{1 1}^{\text {th }}$ in the top league (relegated) & 1995 & Second in the 1 division \\
1983 & Third in the 1 division & 1996 & Second in the 1 division (promoted) \\
1984 & Third in the 1 division & 1997 & $\mathbf{1 1}^{\text {th }}$ in the top league \\
1985 & Second in the 1 division & 1998 & $\mathbf{1 4}^{\text {th }}$ in the top league (relegated) \\
1986 & $7^{\text {th }}$ in the 1 division & 1999 & $5^{\text {th }}$ in the 1 division \\
1987 & Winner of the 1 division (promoted) & 2000 & Third in the 1 division (promoted) \\
1988 & $6^{\text {th }}$ in the top league & 2001 & $\mathbf{8}^{\text {th }}$ in the top league \\
1989 & 11 $^{\text {th }}$ in the top league (relegated) & 2002 & $\mathbf{1 1}^{\text {th }}$ in the top league \\
1990 & Winner of the 1 division (promoted) & 2003 & $\mathbf{8}^{\text {th }}$ in the top league \\
1991 & $\mathbf{9}^{\text {th }}$ in the top league & 2004 & $\mathbf{1 4}^{\text {th }}$ in the top league (relegated) \\
1992 & $\mathbf{1 1}^{\text {th }}$ in the top league (relegated) & 2005 & $7^{\text {th }}$ in the 1 division \\
1993 & Winner of the 1 division (promoted) & & \\
\hline
\end{tabular}

Note: During the period 1981-1994 the number of teams in the Norwegian top league was 12 . The following year the 14-teams league was introduced. During the years from 1981 to 1996 the 1 division (the second level) was divided into two sections, since 1997 there has been only one section. Seasons in the top league is in bold.

Source: www.n3sport.no

The growth in activities and sporting facilities also had the effect of increasing the turnover of Sogndal Fotball. This growth also resulted from events and processes that led to a general growth in turnover of Norwegian top football. This rise was fuelled by the qualification of the Norwegian national team, for the first time ever, for the World Cup in 1994. In addition, Rosenborg of Trondheim established itself as the leading Scandinavian club by qualifying for the Champions League in every year since 1995, except 2003 and 2006. The Norwegian national team again succeeded in qualifying for the World Cup in 1998, as well as the European Championship in 2000. This most successful period in the history of Norwegian football boosted interest in football within the popular media and the public (Jakobsen et al., 2005b). Norway's top football clubs led Scandinavia in the 1990s in terms of net transfers to the large European leagues and in terms of players' wages (Goksøyr and Olstad, 2002). In 2004, the total turnover for the 14 clubs in the Norwegian top league was about NOK 550 million (EUR 70 million). The turnover of Sogndal Fotball increased from NOK 6.6 million in 1995 to an estimated NOK 20 million in 2005. In 1999, 2001, and 2004, turnover was higher than the amount estimated for 2005 (Fig. 3). 
High turnover in these years resulted from income derived from player transfers. In 2004, a NOK 15 million gift to the club from a donor in Bergen made for the highest ever turnover of NOK 45 million.

Much of the increased revenue was spent on new sports facilities, but income was also spent in professionalizing the sport and expanding the administration of the club and associated public limited companies (PLC). At present, Sogndal Fotball takes part in four PLCs: SIL-Tribuna AS (AS is the Norwegian term for PLC), Sognahallen AS, Idrettssenteret AS, and Sogndal Trivsel AS. Employment in Sogndal Fotball and associated PLCs increased from 13 employee-years in 1995 to 41 employee-years in 2004. The increase in employment reflects a shift from amateur to professional contracts for the football players at the club, increasingly professional administrative management of the club, and the increasing administrative requirements as the club has become engaged in new activities.

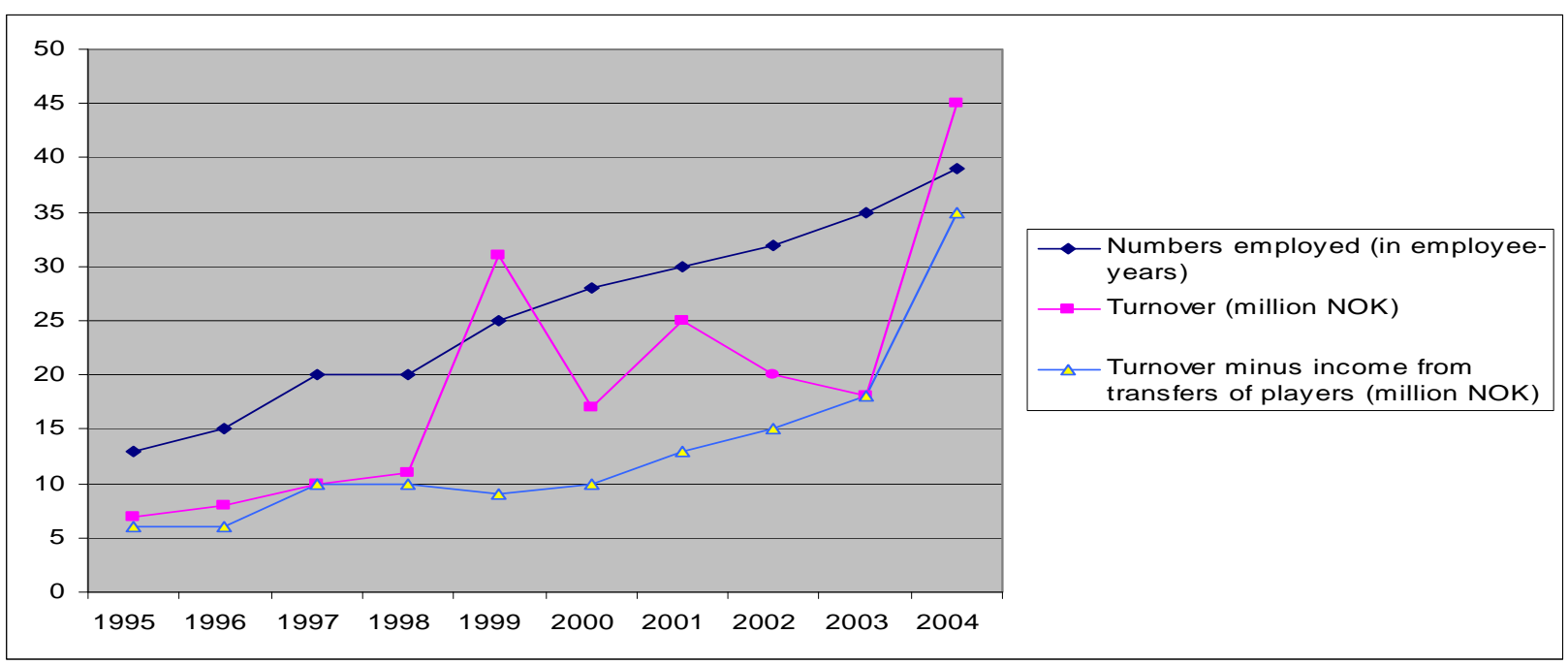

Figure 3: Numbers employed (in employee-years) by Sogndal Fotball, SIL-Tribuna AS, Sognahallen AS, Idrettssenteret AS, and Sogndal Trivsel AS, and turnover of he Sogndal Fotball, 1995-2004.

Source: Sogndal Fotball. 


\subsection{David vs. Goliath}

If clubs from the Oslo area are ignored, the locations of Norway's top football clubs show strong relations between the clubs and a given place. In most cases, identification with a club and a place become mutually reinforcing processes. In Oslo, rivalries exist between top football clubs, and as in most cities, identification with or against top football clubs is structured by the clubs' links to historical class distinctions in specific urban areas. In the Oslo region, competition is also strengthened by clubs that are located outside the municipality boundaries but within the metropolitan region; however, most clubs outside of Oslo do not have a rival top club within their community or in nearby areas (Fig. 4). Most of these clubs are located in municipalities with less than 100,000 inhabitants. In addition, the averages travel time by car between a club outside the Oslo metropolitan area and its nearest competing top club is half a day or more.

Sogndal Fotball is an extreme case when it comes to the scale of population, being based in a municipality of only 6836 inhabitants (2006) in a "back yard" county with about 107,000 inhabitants. All other top football clubs have a much larger population base behind their results (Fig. 4). 


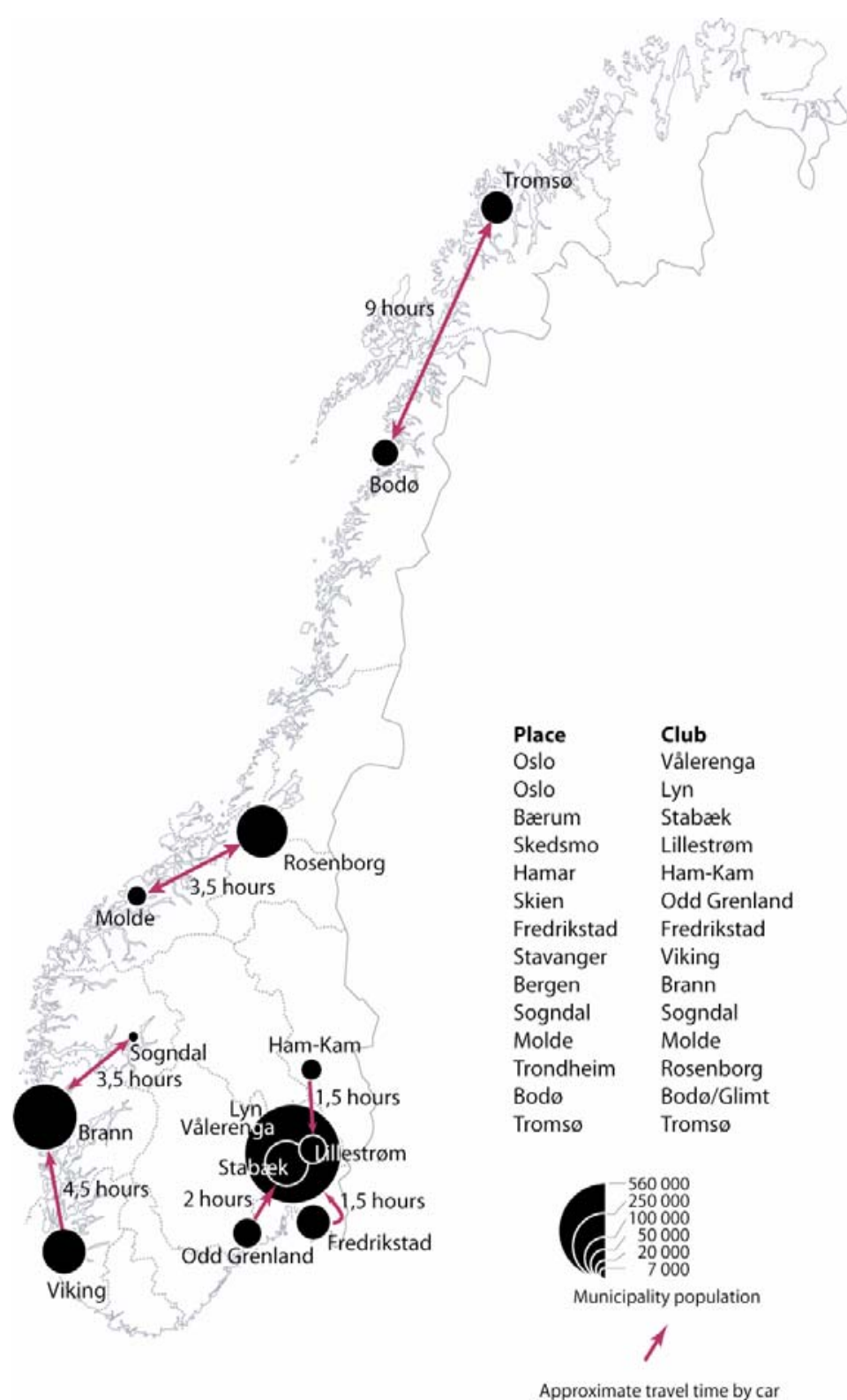

Figure 4: Geographical locations of clubs in the Norwegian top league and distances to nearest rival, 2004. Source: Statistics Norway. Graphic: Kjell H. Sjøstrøm.

Sogndal is very aware of its David vs. Goliath position. It represents itself as the small rural team that, despite its peripheral location and small size, manages to compete with the giant clubs from urban Norway. It is especially common to compare the development of Sogndal Fotball with Sportsklubben Brann, located in Bergen, which is the regional centre of the Vestlandet area: 
We have always compared ourselves with Brann, you have this urban-rural dimension...we like to talk about how small we are, a little community, very scarce resources. (Representative of Sogndal Fotball)

The point is that Bergen is hegemonic to Sogndal in most terms, but not when it comes to organizing a top football club. If the two clubs are compared, Sogndal Fotball has taken the lead in developing sports facilities. It was among the first clubs to construct an indoor hall for football, and its outdoor training grounds are of a much higher standard than those at Brann. In addition, Sogndal Fotball managed its finances well at a time when Brann and other top clubs were running close to bankruptcy. In 2005, Sogndal Fotball began an upgrade of its stadium, once again taking the lead on Brann. In 1991 and 2002, Sogndal even ranked higher than Brann in the top league.

The above aspects are also important when the rural and urban are compared in terms of Sogndal-Sogndal Fotball and Oslo-Vålerenga. A proud moment in the history of Sogndal occurred during the year 2000 when the club defeated Vålerenga in the final qualifying match at Ullevål and was once again promoted to the top league. The relegation of Vålerenga was seen as a disaster by the club and its followers, while the success of Sogndal Fotball had a positive effect on the self-esteem not only of club members, but also of the community at large. As a result, people began to see Sogndal as a rural place that is able to compete with urban places:

Why do we manage this in Sogndal? Why did we obtain an indoor hall before Bergen? In Bergen they are not able at all. Why? Because we are a small community of overlapping networks working together. (Representative of the Sogndal municipality administration)

\subsection{The network model}

New organizational structures have been introduced into the top Norwegian football clubs to ensure the supply of external resources and to obtain an adequate internal resource allocation. Although there is a general tendency towards increasingly professional organization and the formulation of rules and procedures within the clubs, the nature of interaction between 
organizations varies between three models (Jakobsen et al., 2005). The “dual model” is characterized by a contractual connection between the football club and financial actors via a PLC; the "investor model" involves tight relations between the football club and selected investors; and the "network model” is characterized by tight relations between the football club, public authorities, and diverse non-profit and for-profit organizations.

As already demonstrated, Sogndal Fotball rules the ground in Sogndal, and the club has no competition from other top clubs in the community or in the county of Sogn og Fjordane. Thus, conditions in Sogndal favour the network model. As mention in the theory section, networking reaps positive gains of knowledge sharing and the building of trust between actors, which can benefit the development of a social organisation. In many ways, Sogndal occupies an intermediate position in Tönnies’ (1887) dichotomy of Gemeinschaft and Gesellschaft, as used by Durkheim (1889) and Simmel (Wolff, 1950) to theorize and describe the passage from traditional to modern society caused by certain processes labelled "modernization". This theorizing links tradition to "community" (Gemeinschaft) —a society of social people with a collective understanding — and is opposed to "modernity" (Gesellschaft)—a society composed of individuals and impersonal relations of short duration and of rational nature (Fløysand, 1999).

In Sogndal the actors have to balance their interests both as professionals and as community members. This makes everyday life transparent, but it also triggers networking and trust-building:

The place is not that big. When you meet people in different occasions, it might influence the way you behave in professional discussions. It must not be unpleasant to meet at Domus [the local store] after you have finished public discussions (Representative of Sogn og Fjordane University College)

Sogndal is a small place...the former mayor of the municipality married the sister of NN [influential person in Sogndal Fotball]...many hats on each individual actor, you become a part of it. (Representative of Sogndal Fotball)

The club is built on networks... we have to collaborate...cannot afford to be 
isolated...need to build relations towards local politicians, education system, and industry. (Representative of Sogndal Fotball)

We are so few that we all know that if we are not collaborating we will not get anything done. We talk about a very tight milieu. We will not get far if we do not collaborate. (Representative of the municipality administration)

\section{Sogndal Fotball and the commodifaction of Sogndal}

\subsection{Fosshaugane Campus: an emerging narrative}

In Sogndal there are several examples on how Sogndal Footbal has benefited from dense and trust-based linkages between hegemonic actors in the community. This network practice is so sophisticated that it almost has become an "art". In 1995, the future construction of the new indoor football hall became a central issue in the local election campaign. The political party that was pushing hardest for the new hall was led by a former key player at Sogndal; he emerged as the winner of the election and became the new mayor, and the club got its new indoor hall.

The art of networking is also a core element behind the new development project of Fosshaugane Campus. This project is rooted in the needs of multiple "consumers" of a place and stands out as an example of the merging of different representations of a place to market it as attractive to both outsiders and insiders. Sogndal Fotball has been the key actor or "engine" of the project. This role of local entrepreneur arose with the development of a professional administrative management at the club. The administration has a vision of upgrading the club such that it can follow current trends in Norwegian and international football. A multi-function stadium that uses multiple sources of income to increase revenue is seen as an essential feature of a modern football club (Morrow, 2003), but these new multi-function stadiums of European football are located in cities and metropolitan areas of a far larger scale than Sogndal. This makes Sogndal Fotball an extraordinary case.

The development of a modern and professional football organization in Sogndal had already 
begun during the 1980s. Key figures in this development were former players of the 1976 team. The club has been good at retaining past players by placing them in management positions within the club. Such past players combined their knowledge of football with ideas on building an organization that can make the most of limited resources. Those founding members that originally occupied key positions still have a role to play within the organization. This is in line with the literature that states that the ideas of the founders have long-lasting effects on organizational design (Baron et al., 1999). However, since the turn of the century, newcomers have been the entrepreneurs of the organization, but not without maintaining links with the past. The present chief executive at the club does not have a background as a player, but he is well educated, has occupied various positions at Sogn og Fjordane University College, and has been active in local politics. Thus, he knows a lot of people in the community and has comprehensive experience in efforts of rural development. A dense, trust-based and well established network has facilitated the development of Sogndal Footbal. Still, such network runs the risk of "cognitive lock in”. Eventually close friends tend to move in circles. As an outsider to the club the chief executive represent a complementary body of knowledge. Certain knowledge heterogeneity within an organisation is important for the development of new ideas and creativity (Noteboom 2000).

The involvement of Sogndal Fotball in Fosshaugane Campus is linked to events and procedures within the Union of the European Football Associations (UEFA). At the beginning of the new millennium, UEFA strengthened its facility requirements for football stadiums. The Norwegian Football Association (NFF) followed up on these new requirements by offering incentives to top football clubs to upgrade their stadium facilities. Sogndal Fotball has the ambition of being among the top 18 clubs in Norway. This ambition, and the club's earlier success in developing sporting facilities, soon required a plan for a stadium upgrade. The club had to meet the requirements of UEFA-NFF and to present a representation of Fosshaugane (their home ground) that could successfully market the "place" to football players, supporters, and sponsors. Other more pressing needs were to gain acceptance from the community for upgrading the stadium in order to gain access to capital. The stadium upgrade will cost approximately EUR 31 million, with 26 million derived from external sources. Construction will be completed during 2006. 
A key question for members of the club is the kind of narrative that can merge the various needs outlined above. The answer was not Fosshaugane Stadium, but instead Fosshaugane Campus. Fosshaugane Campus is based on representations that are far from what people normally associate with a football stadium. The challenge seems to have been to develop a narrative that is acceptable to the dominant interest groups in Sogndal and to various consumer groups both inside and outside the community. The project was represented as a dream, a goal, a locality, and a melting pot (www.angrip.no) ${ }^{1}$, presented in a collage of drawings and texts (Fig. 5).

The dream is about "creating the best milieu for development in Norway"; the goal "is to build further on the dialectics between intellectual and social development, between entrepreneurship and youthful courage, between the professional and the voluntary"; locality is about "co-location" and "an architecture of the campus that stimulates our competitiveness in relation to others in the struggle to attract students and other users"; and the melting pot is about how "co-location of sport, education, and research has inspired new activities and new firms.” 


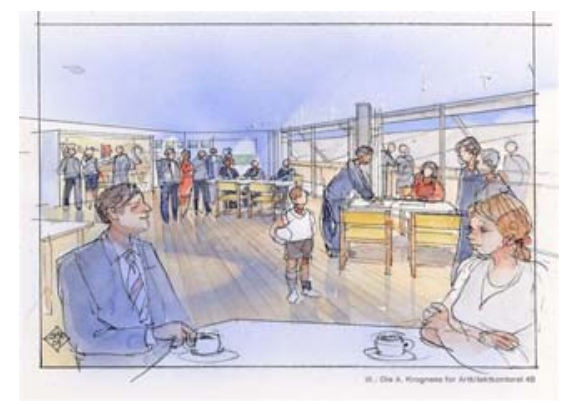

...The dream

The dream of creating the best milieu for development in Norway:

- to stimulate youths and adults to learn from each other

- to stimulate regional development

- to introduce entrepreneurship as a core value

- to build the future of the county

- to build economic know-how.

\section{...The goal}

The goal is to encourage dialogue between intellectual and social development agents, between entrepreneurship and youthful courage, between the professional and the voluntary.

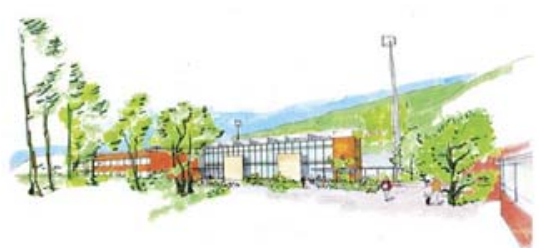

\section{...Locality}

We saved resources via co-location and chose a campus architecture that stimulates our competitiveness in relation to others in the struggle to attract students and other users.

\section{...The melting pot}

Co-location of sport, education, and research will attract new activities and new firms. The combination of sport, exercise, health, and ICT [Information and Communication Technology] has great potential for industrial development. Sognahallen (an established indoor football stadium) has developed into a creative and dynamic milieu where ideas breed and initiatives are quickly realized.

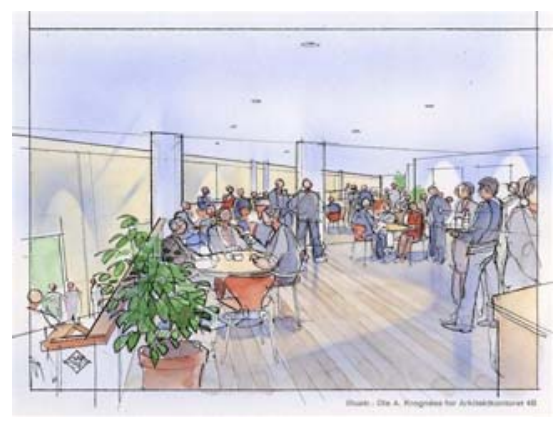




\subsection{The role of Sogndal Fotball in rural development}

The strong position of Sogndal Fotball in the narrative is partly an effect of a perceived shortage of industrial entrepreneurs in the private sector. According to our sources, Sogndal lacks entrepreneurial spirit:

We keep an 8-to-4 culture. When people in Førde [a community in the north of the county] see others work late the reaction is that the guys are working hard. In Sogndal the reaction would be why do they bother working that much? This culture is a problem for us in Sogndal. (Representative of Sogndal Fotball)

In Sogndal there is no industrial cluster which generates new industrial activities. (Representative of Sogn og Fjordane University College)

In contrast, Sogndal Fotball is portrayed as a dynamic industry incubator:

At present the most dynamic industrial actor in the area is the football...not the football in itself, but in the commercialization linked to the sport, the football as niche. (Representative of Sogn og Fjordane University College)

When I started in this job...the most exciting part was that Sogndal Fotball is the most important industrial developer in Sogndal. The role as industrial developer was the most attractive part of the job for me. (Representative of Sogndal Fotball)

The role of Sogndal Fotball as an "industrial incubator" has its material expression in four PLCs (AS). Two PLCs (SIL-Tribuna AS and Sogndal Trivsel AS) are 100\% controlled by Sogndal Fotball, and the club has shares of $18.5 \%$ and $49.5 \%$ in Sognahallen AS and Idrettsenteret AS, respectively. The four PLCs are managed by the administration employed by Sogndal Fotball; hence, all the PLCs are associated with Sogndal Fotball. One of the PLCs, SIL-Tribuna AS, is 
supervising the construction of the new stadium. Since 1990, ties between Sogndal Fotball, Sogn og Fjordane University College, and the municipality have become very tight:

We needed more space. The [national] policy encouraged leasing arrangements. First we leased facilities at Kvale Stadium, later at Fosshaugane. Over time, complementary strategies developed. SIL discovered that it was rational to finance their sports facilities through rent incomes. Sogn og Fjordane University College discovered that the sports facilities of SIL supported the sport education program of the college. (Representative of Sogn og Fjordane University College)

In 1995/1996 'Sport as Industry’ was integrated in the industry development strategy of the municipality...sport means increased industrial employment! SIL is a tool for us, an actor with more independence than the municipality, county, government...if it had not been for SIL we would not have been able [to develop the different sport facilities]...[Sogndal Fotball] is an independent player that is challenging all, if you want to take part you have to join them. (Representative of the municipality)

The above quotations illustrate that the key members of the club and their networks form a dense pattern of trust-based social relations that facilitate the actions of key actors working toward industrial development in Sogndal. These networks form “an industrial incubator field,” which through Fosshaugane Campus is able to market the place to both insiders and outsiders. This field currently includes key actors from most governmental organizations in Sogndal (Sogn og Fjordane University College, Sogndal Secondary School (County Level), Sogndal Municipality), Sogndal Fotball (including related AS), and the Western Norway Research Institute (WNRI). Given the members in this field, we can consider it a social field of local scale.

\subsection{Fosshaugane Campus: a reification}

The needs of the municipal authorities for an industrial incubator do not in itself justify the narrative. The narrative of Fosshaugane Campus has to satisfy the expectations of various other actors such as Sogn og Fjordane University College, Sogndal Secondary School, and the WNRI 
and their partners, including staff, students, and parents. Hence, representations such as “entrepreneurship”, “melting pot”, and "youthful courage” make more sense when the interests of other field members in the industrial incubator field are considered.

Sogn og Fjordane University College is the second-most important actor involved in Fosshaugane Campus, and the campus will provide the college with new infrastructure. The research, education, and administration activities of the University College are spread over different sites. There is therefore a need for a spatial concentration of activities; Fosshaugane Campus, when realized, will fulfil this need. Part of the new college infrastructure will be owned by the college, but a major part will be leased from SIL-Tribuna AS in their new stadium building. The partners have agreed on a 20-year contract for approximately $6000 \mathrm{~m}^{2}$.

Restructuring of the Norwegian education system in general also influences the narrative of Fosshaugane Campus. In recent years the education system in Norway has undergone processes of internationalization and deregulation. The outcome of this restructuring is a more marketoriented system and increased competition for resources, including students. In response to these changes, colleges have developed education profiles to attract students. At Sogn og Fjordane University College, sport is one of the most important profiles. Fosshaugane Campus will offer modern sport facilities and hopefully recruit large numbers of students.

In summary, it can be argued that the main reason for the involvement of Sogn og Fjordane University College in Fosshaugane Campus is the need for a "place" where activities are colocated and a narrative of the site Sogndal, which strengthens its attraction for students. The cost of the planned upgrading of Sogn og Fjordane University College in the Fosshaugane Campus project is estimated to be approximately EUR 29 million. This is an additional local investment to the EUR 31 million earmarked for the stadium upgrade.

More recently, Sogndal Secondary School has become increasingly involved in the campus project. The school is already well settled at Fosshaugane, and is one of the most important users of some of the sport facilities run by Sogndal Fotball and related AS. The school also needs to relocate some of its activities, and its planned investment in the campus area is estimated to be 
about EUR 25 million.

Finally, the WNRI is also involved in the project. The WNRI is a non-profit foundation established in 1985 as an independent research institute. The institute is part of Norway's national research system and cooperates closely with Sogn og Fjordane University College. WNRI employs a staff of 30 and will be a key partner in the "knowledge park" that is integrated into the Fosshaugane Campus project, “where ideas breed and initiatives are quickly realized.”

\subsection{Towards commodification?}

The entrepreneurial mentality of key actors in Sogndal Fotball has been essential in the construction of the industrial incubator field and its main narrative, Fosshaugane Campus. There is a tendency towards increased commodification within this field, but does the practice illustrate complete commodification? As mentioned in the above theoretical discussion, Williams (2002) has identified three distinct elements of commodification. The first element is that goods and services are produced for exchange. The professionalization of Sogndal Fotball implies an increased emphasis on revenue and the development of a more business-minded organization. This has been expressed via the establishment of the four PLCs (AS); the development of a sponsor product, and the undertaking of various tasks designed to increase gate revenue. These initiatives are directed towards developing football as a product that can be exchanged in the market. There is also an increasing market orientation within the Norwegian education system. Sogn og Fjordane University College, the second most important player in the field, is developing specific education profiles to attract students. Students are viewed as customers shopping in an education market.

The second element related to commodification described by Williams (2002) is that the activity within a field is monetized and conducted under market conditions. The employment of players, coaching staff, and administrators implies that the relationship between the organization (Sogndal Fotball) and individuals has been monetized in the industrial incubator field. In recent decades, a market has emerged for the trading of football players. However, not all of the relations between Sogndal Fotball and its individuals or members have been monetized: there remain large numbers 
of volunteers who contribute to the club. These volunteers are especially important on match day in their roles as guards, ticket sellers, and refreshment vendors. Volunteers are a vital part of Norwegian football, but it is difficult to measure the exact amount of unpaid work. In contrast, Sogn og Fjordane University College has a more strictly monetized relationship with individuals and members. This is also the case for other important players in the industrial incubator field, such as Sogndal Secondary School, the Western Norway Research Institute, and the Municipality of Sogndal.

Williams' (2002) final element related to commodification is that the activity should be motivated by the pursuit of profit. It is difficult to determine if the pursuit of profit is the driving force of the key actor in this case, Sogndal Fotball. We stated that the club has become more business-minded, but its main target is to develop a football team that is the pride of the organization and the community. The activity of the club is not directed by seeking rental income or the motive of a certain rate of return for its members or shareholders. Thus, the profit motive is not essential to the activity of the club; however, during the past decade there has been a growing recognition within the organization that increased revenues are a prerequisite for good sports results. In the case of Sogn og Fjordane University College and the Western Norway Research Institute, the profit motive appears to be absent: both have clearly stated that they are non-profit organizations. The aim of these organizations is to develop their knowledge bases and positions as key players in efforts to develop the region.

Even if there is a movement towards increased commodification among the members of the industrial incubator field at Sogndal, the situation is far from one of complete commodification. This is demonstrated by the use of volunteers in organizing the football club and the lack of profit motive among the field members. Other studies that have examined alternative economic spaces confirm that monetary exchanges are not always necessarily imbued with the profit motive (Crewe and Gregson, 1998). Williams (2002) stated that even in advanced societies there are large alternative economic spaces that lack some of the logic of commodification, and that there is a certain culture of resistance to the edicts of commodification. Our analysis of the industrial incubator field of Sogndal supports this line of thought. In terms of commodification, the field is a hybrid form that combines individual and collective needs. 


\section{Conclusions}

The narrative of social fields, rural development, and football presented in this paper exemplifies a practice of rural restructuring linked to commodification of rural places that expresses both internal and external connections between the material and imaginative worlds of the rural (Cloke, 2006). In recent decades, the football club of the municipality of Sogndal has become a symbol of the successful underdog in top-level Norwegian football. The Norwegian Football Association has used Sogndal Fotball to exemplify the fact that it is not just the size of the budget or gate revenue that determines success in the money-spinning era of modern football. One outcome of the success of the club is positive self-esteem in the community. The football club has taken the lead in developing sports facilities and establishing them as corporations, adding four PLCs to the original Sogndal Fotball. This has strengthened Sogndal Football's position as an industrial developer; consequently, the ties between the club, Sogn og Fjordane University College, and local authorities have become very tight.

Another outcome of the activities of the club and its associate PLCs is Fosshaugane Campus. Fosshaugane Campus is a key practised narrative in a rural development project that combines a stadium upgrading with the development of education and research facilities. Development of the campus is based on both "material" and "imaginative" events and processes within football, education systems, and rural development. The narrative demonstrates how commodification of rural areas can be rooted in the emerging trends of football in Europe, including growth in turnover, the increasingly professional organization of football clubs, and in social fields at a local scale whereby the supply of resources is organized via networks and trust-based linkages between members of football clubs, public authorities, and other important local institutions.

"Fosshaugane Campus" is also a practice that merges different imaginative representations that together brand the rural in such a way that it can be accepted by different interest groups in the community and by multiple consumer groups outside the community. The categories that are employed are vague, and as such can be associated with a wider system of representations promoted by actors in the industrial incubator field, which is a hegemonic social field at a local 
scale. The local top football club is a key actor in this field, and as such demonstrates how a football club can take a leading role in processes of commodification of rural places.

In certain aspects, this case differs from most rural commodity cases discussed in the literature. First, it clearly illustrates that the construction of narratives that target the commodification of rural places occurs in social fields. Narratives are not universally shared in a post-modern world, but the dominance of certain narratives in certain hegemonic social fields is fundamental for the commodification of rural places. Second, this case illustrates that the producers, as well as potential consumers, of the countryside as a commodity can be "insiders" within a community. Third, the narrative of social fields, rural development, and football exemplifies how time-space compression acts to develop rural places into a form of commodity, albeit very different from the representations produced within the tourist gaze. In the present case, the countryside is branded as a place of "development, entrepreneurship, and youthful courage”, which differentiates the process from representations of the countryside developed by outsiders for a special market segment such as tourists. The case also demonstrates how commodification of rural places is constructed through time-space compression, in which multiple actors are involved. There are also multiple potential consumers such as tourists, investors, sponsors, football players, villagers, potential immigrants to the region, and relocating firms. These various consumers can be attracted by a range of different representations of the countryside. In such settings that involve multiple actors, the challenge is to construct a hegemonic narrative that is accepted by most producers and consumer groups. The only thing that seems to glue the actors together in such circumstances is a hybrid "capitalist gaze” that brands the place as a commodity. 


\section{Footnotes}

1. The website www.angrip.no is in Norwegian. The captions have been translated into English by the authors. 


\section{References}

Amin, A. and Cohendet, P. (1999) Learning and Adaptation in Decentralised Business Networks. Environment and Planning D: Society and Space 17, 87-104.

Augé, M. (1995) Non-Places: Introduction to an Anthropology of Supermodernity. Verso, London.

Baron, J.N., Burton, M.D and Hannan, M.T. (1999) Engineering bureaucracy: the genesis of formal policies, positions, and structures in high-technology firms. Journal of Law, Economics and Organization 15, 1-41.

Bathelt, H., Malmberg, A. and Maskell, P. (2004) Clusters and knowledge: local buzz, global pipelines and the process of knowledge creation. Progress in Human Geography 28, 3156.

Bell, D. and Valentine, G. (1995) Queer country: rural lesbian and gay lives. Journal of Rural Studies 11, 113-122.

Binns, S., Hamil, S., Holt, M., Michie, J., Oughton, C., Shailer, L. and Wright, K. (2002) The State of the Game: The Corporate Governance of Football Clubs 2002. Football Governance Research Centre, University of London.

Burt, R. (1992): Structural holes: The social structure of competition. Harvard University Press, New York.

Cashman, R. (2002) Sport in the National Imagination. Walla Walla Press, Sydney.

Cloke, P. (1989) Rural Geography and Political Economy. In: New Models in Geography: The Political Economy Perspective, vol. 1, Peet, R. and Thrift, N. (eds). Unwin Hyman, London, pp.164-197.

Cloke, P. (2006) Conceptualizing Rurality. In: The Sage Handbook of Rural Studies, Cloke, P., Marsden, T. and Mooney, P.H. (eds). Sage, London, pp.18-28.

Cloke, P., Marsden, T. and Mooney, P.H. (2006) The Sage Handbook of Rural Studies. Sage, London.

Chisholm, M. (1962) Rural Settlement and Land Use. Hutchinson, London.

Crewe, L. and Gregson, N. (1998) Tales of the unexpected: exploring car boot sales as marginal spaces of contemporary consumption. Transaction of the Institute of British Geographers 23, 39-54.

Durkheim, E. (1889) Tönnies, F., Gemeinschaft und Gesellschaft. Revue Philosophique 27, 416433 (in German). 
Fardal, J.I. (2001) Frå pølsebu til storhall. Sogdal Idrettslag 1976-2001. AIT Otta as, Otta. (in Norwegian)

Fløysand, A. (1999) A theoretical framework on how to approach globalization and social practice. In: Occasional Paper, Human Geography 26, Fraas, M. and Stokke, K. (eds), pp. 125-133.

Fløysand, A. and Jakobsen, S.-E. (2002) Clusters, social fields and capabilities: rules and restructuring in Norwegian fish processing clusters. International Studies of Management and Organisation 31, 36-57.

Fløysand, A. and Jakobsen, S.-E. (2005) The embeddedness of industries: a time-geographical approach. Nordisk Samhällsgeografisk Tidsskrift 39, 88-125.

Gammelsæter, H. and Ohr, F. (2002) Kampen uten ball. Om penger, ledelse og identitet i norsk fotball. Oslo: Abstrakt (in Norwegian).

Goksøyr, M. and Olstad, F. (2002) Fotball! Norges fotballforbund 100 år. Norges fotballforbund (in Norwegian).

Gordon, I.R. and McCann, P. (2000) Industrial Clusters: Complexes, Agglomerations and/or Social Networks? Urban Studies 37, 513-532.

Granovetter, M. (1985): Economic action and social structure: The problem of embeddedness. American Journal of Sociology 91, 481-450.

Gregson, N. (1995) And now it’s all consumption. Progress in Human Geography 19, 135-141.

Grønhaug, R. (1974) Micro Macro Relations. Sosialantropologisk Institutt. Universitetet i Bergen, Bergen.

Haarstad, H. (2005) Globalized Power and Resistance: A Peruvian Case Study Demonstrating Embeddedness in Spatial Scales. Masters thesis, Department of Geography, University of Bergen.

Hague, E. and Mercer, J. (1998) Geographical memory and urban identity in Scotland: Raith Rovers FC and Kirkcaldy. Geography 83, 105-116.

Halfacree, K. (2006) Rural Space: Constructing a Three-fold Architecture. In: The Sage Handbook of Rural Studies, Cloke, P., Marsden, T. and Mooney, P.H. (eds), Sage, London, pp.44-62.

Hall, D., Roberts, L. and Mitchell, M. (2003) New Directions in Rural Tourism. Ashgate, Aldershot.

Hamil, S. (1999) Football clubs as social or financial institutions? Football Governance Research 
Centre, University of London.

Hoggart, K. and Paniagua, A. (2001) What rural restructuring? Journal of Rural Studies 17, 4162.

Hompland, A.H. (1981) Sogdal e laget. Det Norske Samlaget, Oslo (in Norwegian).

Ilbery, B. (ed.) (1998) The Geography of Rural Change. Longman, London.

Jakobsen, S.-E., Rusten, G. and Fløysand, A. (2005a) How green is the valley? Foreign direct investment in two Norwegian industrial towns. The Canadian Geographer 49, 244-259.

Jakobsen, S.-E., Gammelsæter, H., Fløysand, A. and Nese, G. (2005b) The transformation of organisational structures within Norwegian elite football: towards formalization. Paper presented at the 13th Congress of the European Association for Sport Management at Newcastle-Gateshead, England, 7th and 10th September 2005.

Kinsman, P. (1995) Landscape, race and national identity. Area 27, 300-310.

Little, J. and Austin, P. (1996) Woman and the rural idyll. Journal of Rural Studies 12, 101-111.

Marsden, T. (1995) Beyond agriculture: regulating the new rural spaces. Journal of Rural Studies 11, 285-297.

Maskell, P., Eskelinen, H., Hannibalson, I., Malmberg, A. and Vatne, E. (1998) Competitiveness, Localised Learning and Regional Development: Specialisation and Prosperity in Small Open Economies. Routledge, London.

Morgan, K. (1997) The learning region: institutions, innovation and regional renewal. Regional Studies 31, 491-503.

Morrow, S. (2003) The People’s Game? Football, Finance and Society. Palgrave Macmillan, New York.

Murdoch, J. and Marsden, T. (1994) Reconstituting Reality: Class, Community and Power in the Development Process. USL Press, London.

Nohria, N. (1992) Introduction: Is a nework perspective a useful way of studying organizations? In: Nohria, N. and Eccles, R.G. (eds) Network and Organizations. Structure, form and action. Harvard Business School Press, Boston, pp. 1-22.

Noteboom, B. (2000) Learning and Innovation in Organizations and Economies. Oxford University Press:, Oxford.

Phillips, M. (1998) The restructuring of social imaginations in rural geography. Journal of Rural Studies 14, 121-153. 
Polanyi, K. (1957) The Great Transformation. Beacon Press, Boston.

Swyngedouw, E. (2004) Globalisation or 'glocalisation'? Networks, territories and rescaling. Cambridge Review of International Affairs 17, 25-48.

Swyngedouw, E. (1997) Excluding the Other: the Production of Scale and Scaled Politics. In: Geographies of Economies, Lee, R. and Wills, J. (eds). Arnold, London.

Thrift, N. (1987) Manufacturing rural geography. Journal of Rural Studies 3, 77-81.

Tonts, M. (2005) Competitive sport and social capital in rural Australia. Journal of Rural Studies 21, 137-149.

Tönnies, F. (1887) Gemeinschaft und Gesellschaft: Grundbegriffe der reinen Soziologie. Curtius, Berlin.

Urry, J. (1990) The Tourist Gaze: Leisure and Travel in Contemporary Societies. Sage Publications, London.

Urry, J. (1995) A Middle-class Countryside? In: Consuming Places, Urry, J. Routledge, London, pp.211-229.

Urry, J. (2002) The Tourist Gaze. Second Edition. Sage Publications, London.

Walker, G. (1988): Network analysis for cooperative interfirm relationships, In: Comparative strategies in International Business, Contractor, F. and Lorange, P. (eds). Rowman \& Littlefield, Lexington, pp.227-240.

Watts, M. (1999) Commodities, In: Introducing Human Geographies, Cloke, P., Crang, P. and Goodwin, M. (eds). Arnold, London.

Williams, C.C. (2002) A critical evaluation of the commodification thesis. The Sociological Review 50, 525-542.

Williams, W. (1963) A West Country Village: Ashworthy. Routledge and Kegan Paul, London.

Wolff, K.H. (1950) The Sociology of Georg Simmel. The Free Press, Glencoe.

Woods, M. (2005) Rural Geography. Sage Publications, London. 